\title{
Fracture Forces of Dentin after Surface Treatment with High Speed Drill Compared to Er:YAG and Er,Cr:YSGG Laser Irradiation
}

\author{
Rene Franzen, ${ }^{1,2}$ Nasrin Kianimanesh, ${ }^{2}$ Rudolf Marx, ${ }^{3}$ \\ Asma Ahmed, ${ }^{2}$ and Norbert Gutknecht ${ }^{1}$ \\ ${ }^{1}$ Department of Conservative Dentistry, Periodontology and Preventive Dentistry, RWTH Aachen University Hospital, \\ Pauwelsstrasse 30, 52074 Aachen, Germany \\ ${ }^{2}$ AALZ Aachen Dental Laser Center, Center for Biomedical Technology, RWTH Aachen Campus, Pauwelsstrasse 17, \\ 52074 Aachen, Germany \\ ${ }^{3}$ Medical Material Science, RWTH Aachen University Hospital, Pauwelsstrasse 30, 52074 Aachen, Germany
}

Correspondence should be addressed to Rene Franzen; rfranzen@ukaachen.de

Received 13 November 2015; Accepted 12 January 2016

Academic Editor: Kenji Yoshida

Copyright (c) 2016 Rene Franzen et al. This is an open access article distributed under the Creative Commons Attribution License, which permits unrestricted use, distribution, and reproduction in any medium, provided the original work is properly cited.

\begin{abstract}
Dental tooth restorative procedures may weaken the structural integrity of the tooth, with the possibility of leading to fracture. In this study we present findings of coronal dentin strength after different techniques of surface modification. The fracture strength of dentin beams after superficial material removal with a fine diamond bur high speed drill hand piece, Er:YAG $\left(2.94 \mu \mathrm{m}, 8 \mathrm{~J} / \mathrm{cm}^{2}\right)$, and Er,Cr:YSGG $\left(2.78 \mu \mathrm{m}, 7.8 \mathrm{~J} / \mathrm{cm}^{2}\right)$ laser irradiation slightly above the ablation threshold was measured by a four-point bending apparatus. Untreated dentin beams served as a control. A total of 58 dentin beams were manufactured from sterilized human extracted molars using the coronal part of the available dentin. Mean values of fracture strength were calculated as $82.0 \pm 27.3 \mathrm{MPa}$ for the control group $(n=10), 104.5 \pm 26.3 \mathrm{MPa}$ for high speed drill treatment $(n=10), 96.1 \pm 28.1 \mathrm{MPa}$ for Er,Cr:YSGG laser irradiation $(n=20)$, and $89.1 \pm 36.3 \mathrm{MPa}$ for Er:YAG laser irradiation $(n=18)$. Independent Student's $t$-tests showed no significant difference between each two groups $(p>0.05)$. Within the parameter settings and the limits of the experimental setup used in this study, both lasers systems as well as the high speed drill do not significantly weaken coronal dentin after surface treatment.
\end{abstract}

\section{Introduction}

Factors related to tooth fracture have been investigated in different studies [1-3]. It is one of the most dramatic clinical situations which might be of concern to both dentists and patients, because it may consequently end up in loss of tooth structure. Therefore, the structural integrity of teeth under stress and how it may be jeopardized by different types of cracks is a very important issue [4]. The maximum stress by itself does not contribute to crack growth but the process of fatigue cycling results in producing cracks on the tooth surface [5]. The fatigue crack growth in human dentin is dependent on variables such as age, tubule orientation and density, and depth below the dentin-enamel junction [6-8].

Understanding the mechanical behavior of dentin under different conditions is crucial. Nevertheless, tooth fracture is multifactorial and restored teeth are more subject to experience cracks and damage during cutting and cavity preparation. Since cracking of teeth can have serious clinical consequences, the technique of cutting has a significant influence on the mechanical properties of the tooth by introducing and initiating cracks during cutting [1, 5, 9-11].

Though cracks of depths up to $71 \mu \mathrm{m}$ were observed after diamond preparation in enamel, Banerjee et al. (2000) did not find cracks in dentin resulting from the use of burs but reported that sono-abrasion and Carisolv gels "caused flaws" $[1,3]$. Yan et al. (2009) on the other hand did not observe flaws within dentin after bur treatment but nevertheless stated that material removal may be related to the cause of fracture [12]. Majd et al. (2012) evaluated the influence of 6-flute tungsten carbide bur and abrasive air-jet with $50 \mu \mathrm{m}$ abrasive particles for cavity preparations on the mechanical behavior of coronal 
TABLE 1: Exact dimensions, breaking force, and bending strength of the untreated control (group 1). The mean value of the bending strength is $82.02 \mathrm{MPa}$ with a standard deviation of $27.25 \mathrm{MPa}$.

\begin{tabular}{lcccc}
\hline Number & Thickness/mm & Width/mm & Breaking force/N & Bending strength/MPa \\
\hline 1 & 1.20 & 1.90 & 37.90 & 112.20 \\
2 & 1.96 & 1.60 & 84.00 & 110.70 \\
3 & 1.36 & 1.90 & 32.00 & 73.76 \\
4 & 1.44 & 1.88 & 6.58 & 13.67 \\
5 & 1.77 & 1.66 & 55.30 & 86.13 \\
6 & 1.58 & 1.86 & 45.20 & 78.85 \\
7 & 1.37 & 1.85 & 37.20 & 86.78 \\
8 & 1.40 & 1.86 & 38.00 & 84.43 \\
9 & 1.30 & 1.75 & 34.40 & 94.21 \\
10 & 1.88 & 1.77 & 61.40 & 79.50 \\
\hline
\end{tabular}

dentin. The results were compared with the strength of intact control beams. Both methods significantly decreased the fatigue strength of dentin. In the same study, for the bur treatment an overall degradation in the endurance limit of nearly $40 \%$ was reported together with an accompanying decrease in fatigue life. It was considered a "critical issue" since this may hinder the dentin to provide a sound foundation for restorative materials [13]. When mechanical instrumentation is used, friction generates heat and hence elevated temperatures, which may cause irreversible damage to the tooth, while the tooth surface shows signs of thermal and mechanical damage in conjunction with a mechanically created smear layer that is formed as a consequence of this technique [14].

Current lasers for hard tissue preparation have been investigated for their abilities to ablate human enamel, dentin, and bone. Among the current commercially available laser systems, the radiation of the erbium lasers (Er:YAG $2.94 \mu \mathrm{m}$ and Er,Cr:YSGG $2.78 \mu \mathrm{m}$ ) is strongly absorbed in water and mineral components and therefore offers the possibility for removal of hard tissues, caries removal, and cavity preparation with minimally invasive concept and more patient comfort. These lasers allow ablation of hard dental tissues without causing injury to the pulp or significant thermal side effects such as cracking, melting, or charring of the adjacent tissues at rates comparable with high speed dental drills and with less pain and vibration, as long as they are used with correct laser parameters and water sprays [15-20].

In a study by Maung et al. only 2 of the 15 samples ablated with the laser showed the formation of small cracks while 9 out of 15 samples exhibited crack formation with the dental hand piece [21]. Sehy and Drummond (2004) prepared class I or class II MOD cavities in molars using either a high speed hand piece with coarse diamond bur or an Er:YAG laser. The preparation was followed by placement of a resin composite, bulk curing to maximize interfacial stresses, and evaluation of the tooth-composite interface by scanning electron microscopy was performed. Neither method of preparation resulted in consistent or significant evidence of microcracking in dentin [22].

Staninec et al. compared a free-running pulsed Er:YAG laser (pulse duration $135 \mu$ s) with a q-switched Er,Cr:YSGG laser (pulse duration $0.5 \mu \mathrm{s}$ ). The $135 \mu$ s pulsed did not create any visible cracks on the irradiated surfaces while the q-switched systems with a 270 times shorter pulse duration, which was additionally operated without an air/water spray, created significant surface cracks from which fractures formed under bending of the specimens [23], pointing out the importance of pulse duration (nanosecond versus microsecond domain) and sufficient water sprays.

The present study addresses the question whether erbium laser surface treatment with fluencies close to the ablation threshold as found for a stopping ablation front in a freerunning mode (microsecond domain) may cause weakening of dentin.

\section{Materials and Methods}

Caries-free extracted human molars were collected and completely cleaned of calculus and debris and then sterilized by $\gamma$-irradiation $\left(\mathrm{Co}^{60}\right)$ minimum absorbed dose of $29 \mathrm{KG}$. The teeth had been extracted for orthodontic reasons by cooperating dental offices and were donated to science.

The teeth were embedded in resin (Technovit 4000/4002: Heraeus-Kulzer, Wehrheim, Germany) and sectioned in buccolingual direction and then in mesiodistal direction to prepare dentin beams approximately $1.5 \mathrm{~mm} \times 1.5 \mathrm{~mm} \times$ $9 \mathrm{~mm}$. The beams were roughly shaped with 400 grit and finished with 800 grit. The procedure of preparing dentin beams was adopted from the description of Staninec et al. [23]. The final dimensions after polishing are listed in Tables 1-4. The buccal surface was marked for later orientation of the specimen. The teeth and beam samples were stored in distilled water throughout the experiment with $0.9 \% \mathrm{NaCl}$.

The beams were assigned to two laser groups each containing 20 samples (groups 3 and 4) and two control groups each containing 10 samples (groups 1 and 2). In the control groups beams were kept either untreated (group 1), serving as a negative control, or treated with a fine diamond bur in a high speed hand piece under water cooling (group $2)$, serving as a positive control.

In the laser groups 3 and 4 beams were irradiated by either a free-running Er:YAG laser system $2.94 \mu \mathrm{m}$ (Lightwalker system, Fotona d.d., Slovenia) or a free-running Er,Cr:YSGG 
TABLE 2: Exact dimensions, breaking force, and bending strength of the Er,Cr:YSGG irradiated specimens (group 2). The mean value of the bending strength is $96.08 \mathrm{MPa}$ with a standard deviation of $28.08 \mathrm{MPa}$.

\begin{tabular}{lcccc}
\hline Number & Thickness/mm & Width/mm & Breaking force/N & Bending strength/MPa \\
\hline 1 & 1.49 & 1.90 & 35.70 & 68.55 \\
2 & 1.65 & 1.80 & 59.80 & 98.84 \\
3 & 1.54 & 1.87 & 67.70 & 123.65 \\
4 & 1.83 & 1.46 & 89.10 & 147.61 \\
5 & 1.16 & 1.88 & 21.20 & 67.88 \\
6 & 1.64 & 1.95 & 72.10 & 111.35 \\
7 & 1.27 & 1.75 & 37.30 & 107.04 \\
8 & 1.38 & 1.89 & 33.10 & 74.49 \\
9 & 1.50 & 1.83 & 61.20 & 120.39 \\
10 & 1.20 & 1.80 & 18.00 & 56.25 \\
11 & 1.44 & 1.74 & 27.40 & 61.51 \\
12 & 0.93 & 1.70 & 111.83 \\
13 & 1.07 & 1.86 & 27.90 & 106.12 \\
14 & 1.14 & 1.87 & 70.66 \\
15 & 1.68 & 1.88 & 7.20 & 121.05 \\
16 & 1.55 & 1.73 & 79.30 & 149.09 \\
17 & 1.14 & 1.90 & 24.50 & 68.25 \\
18 & 1.13 & 2.37 & 25.50 & 110.95 \\
20 & 1.98 & 1.00 & 53.70 & 79.67 \\
\hline
\end{tabular}

TABLE 3: Exact dimensions, breaking force, and bending strength of the Er:YAG irradiated specimens (group 2). The mean value of the bending strength is $89.12 \mathrm{MPa}$ with a standard deviation of $36.32 \mathrm{MPa}$.

\begin{tabular}{lcccc}
\hline Number & Thickness/mm & Width/mm & Breaking force/N & Bending strength/MPa \\
\hline 1 & 1.27 & 1.76 & 33.00 & 94.16 \\
2 & 1.02 & 1.86 & 36.00 & 150.69 \\
3 & 1.24 & 1.88 & 25.90 & 72.57 \\
4 & 2.00 & 1.22 & 70.50 & 117.02 \\
5 & 1.86 & 1.22 & 30.70 & 58.92 \\
6 & 1.57 & 1.70 & 60.00 & 115.98 \\
7 & 1.45 & 1.92 & 60.10 & 120.59 \\
8 & 1.64 & 1.85 & 38.60 & 62.84 \\
9 & 1.26 & 1.90 & 27.70 & 74.38 \\
10 & 1.75 & 1.84 & 61.00 & 131 \\
11 & 1.59 & 1.50 & 18.40 & 71.68 \\
12 & 1.14 & 1.60 & 31.50 & 53.07 \\
13 & 1.75 & 1.57 & 90.60 & 105.05 \\
14 & 1.97 & 29.00 & 60.01 \\
15 & 1.80 & 118.00 & 147.76 \\
16 & 1.94 & 1.04 & 63.10 & 86.67 \\
18 & 1.98 & 1.65 & 38.90 & 55.47 \\
\hline
\end{tabular}

$2.79 \mu \mathrm{m}$ (iPlus system, Biolase Inc., Irvine, CA, USA) both with a total radiation exposure of 10 seconds while their laser beams were scanned along the whole length of the dentin beams with one back and forth motion in mesiodistal direction and vice versa.

Parameters used in the groups were as follows:

(i) Group 1: untreated control (negative control).

(ii) Group 2: fine diamond bur in a high speed hand piece with water cooling (positive control). (iii) Group 3: Er,Cr:YSGG used with a "Gold" type hand piece, MZ6 glass tip (diameter $600 \mu \mathrm{m}$ ), pulse duration $60 \mu \mathrm{s}, 25 \mathrm{~mJ}, 10 \mathrm{~Hz}$, water $80 \%$, air $50 \%$ (adjustable spray), and fluence $8 \mathrm{~J} / \mathrm{cm}^{2}$ on the specimen's surface.

(iv) Group 4: Er:YAG laser used with an "H14" hand piece, glass tip (diameter $800 \mu \mathrm{m}$ ), pulse duration $100 \mu \mathrm{s}$, $40 \mathrm{~mJ}, 10 \mathrm{~Hz}$, water $60 \%$, air $40 \%$ (adjustable spray), and fluence $7.8 \mathrm{~J} / \mathrm{cm}^{2}$ on the specimen's surface. 
TABLE 4: Exact dimensions, breaking force, and bending strength of the specimens treated by fine diamond bur in a high speed hand piece (group 1). The mean value of the bending strength is $104.47 \mathrm{MPa}$ with a standard deviation of $26.31 \mathrm{MPa}$.

\begin{tabular}{lcccc}
\hline Number & Thickness $/ \mathrm{mm}$ & Width/mm & Breaking force/N & Bending strength/MPa \\
\hline 1 & 1.15 & 2.12 & 39.90 & 115.27 \\
2 & 1.75 & 1.05 & 34.20 & 86.15 \\
3 & 1.12 & 1.89 & 24.40 & 83.36 \\
4 & 1.55 & 1.81 & 44.10 & 82.15 \\
5 & 1.56 & 1.67 & 49.10 & 97.86 \\
6 & 1.35 & 1.79 & 48.20 & 119.68 \\
7 & 1.40 & 1.79 & 33.60 & 77.57 \\
8 & 1.65 & 1.87 & 55.90 & 88.94 \\
9 & 2.00 & 1.09 & 78.70 & 146.21 \\
10 & 1.57 & 1.86 & 83.50 & 147.52 \\
\hline
\end{tabular}

Note that different pulse energies were chosen in groups 2 and 3 to compensate for different glass tip diameters of the laser systems in order to achieve a similar fluence. Around $4 \mathrm{~J} / \mathrm{cm}^{2}$ has been reported for the ablation threshold of dentin for Er:YAG laser irradiation [23, 24].

Laser parameters for groups 3 and 4 were chosen in such a way that the treated surface of the dentin beams was exposed to fluencies similar to those at the bottom of laser created cavities. While such cavities are obviously being created with significantly higher fluencies (in the order of $60 \mathrm{~J} / \mathrm{cm}^{2}$ for typical clinically used energies of $300 \mathrm{~mJ}$ and a beam cross section of $800 \mu \mathrm{m}$ ), the point where the ablation front stops moving into the dentin, hence the ablative process stopping, is where the newly created cavity floor is found. Therefore, the decision to use fluencies slightly above the ablation thresholds of $7-8 \mathrm{~J} / \mathrm{cm}^{2}$ was chosen to allow a slight ablative material removal with the ablation front stopping just inside the specimens. Only very little material is expected to be removed from the specimens themselves as due to their dimension for the fracture tests, they would be damaged or broken by the laser pulses if higher fluencies or removal rates are used. Instead, a dentin surface such as being found at a cavity floor is being simulated. Additionally, the dentin beam is irradiated on one surface side only, similar to that in a clinical dentin laser preparation, and the dentin is irradiated from one side.

In a similar fashion, the use of the diamond bur in the control group was moved manually along the length of the dentin beam, allowing it to remove material close to the surface and hence again simulating the floor of a burprepared excavation. Note that no EDTA or any similar agent was used to remove the created smear layer. Additionally, we point out that within the limits of our study design we cannot factor in additional sources of stress that could be found in a clinical situation such as forceful movement of the bur creating microfractures or high pulse energies for the laser systems creating similar incidences; however, to our knowledge the latter incidences have not been reported in the literature for free-running pulsed lasers.

Treated surfaces were oriented perpendicularly to the marked buccal surface; hence the direction of dentinal tubules was perpendicular to the treated surface and parallel to the direction of force of the bending test. That would be the same direction as the functional force naturally occurs. Each dentin beam was placed in a mechanical testing machine in a four-point bending apparatus (Zwick/Roell Z5.0, Zwick $\mathrm{GmbH}$, Ulm, Germany) and tested with increasing load at a displacement rate of $1 \mathrm{~mm} / \mathrm{min}$ until failure. The bending strength $B$ can be calculated as shown in what follows:

$$
B=\frac{3(l-c) F}{2 b h^{2}}
$$

using the following variables: $l=$ lower distance of loading points $=7.2 \mathrm{~mm}, c=$ upper distance of loading points $=$ $1.8 \mathrm{~mm}, b=$ width of the samples, $h=$ thickness of the samples, and $F=$ breaking force.

Each beam was positioned in a four-point bending apparatus with $1.8 \mathrm{~mm}$ distance to the upper loading points and $7.2 \mathrm{~mm}$ to the lower loading points until fracture occurred under the load. Load at fracture recorded as breaking force $F$ and bending strength $B$ of each beam was calculated accordingly.

\section{Results}

Final dimensions of the dentinal beams after preparation, breaking force, and bending strength are shown in Tables 1-4.

Mean values of bending strength were calculated as $82.0 \pm$ 27.3 MPa for the unprepared control group, 96.1 $\pm 28.1 \mathrm{MPa}$ for Er,Cr:YSGG laser irradiation, $89.1 \pm 36.3 \mathrm{MPa}$ for Er:YAG laser irradiation, and $104.5 \pm 26.3 \mathrm{MPa}$ for high speed drill conditioned surfaces. These values are presented in Figure 1. Independent $t$-tests showed that there were no significant differences between each two groups $(p>0.05)$.

\section{Discussion}

The effect of erbium family lasers on tooth structure during cavity preparation has been investigated in several studies. Various pulse durations and repetition rates and different energy and power parameters were investigated in these studies regarding the micromorphological aspect of enamel and dentin, ablation speed, depth, and/or volume [15, 25-31]. 


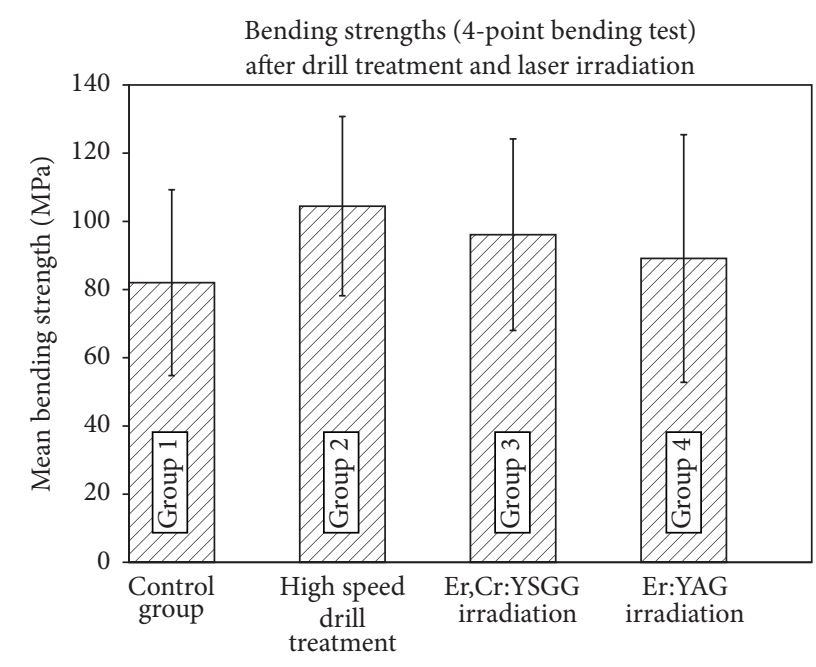

FIGURE 1: Illustration of the 4-point bending test results showing bending strengths for the control and the 3 test groups.

On the other hand, bur tooth preparation is associated with metallic noise and vibration that might cause discomfort and anxiety of the patient, as well as cracks and tooth weakening $[1,13,21]$. Less pain, noise, and vibration have been reported with laser cavity preparation $[17,32]$. Bactericidal and anti-infective effects are the other aspects that could be expected [33].

Staninec et al. described a difference regarding fracture under bending between a free-running Er:YAG laser of $135 \mu \mathrm{s}$ and a q-switched Er,Cr:YSGG laser of $0.5 \mu$ s pulse duration. While the Er:YAG treated surfaces did not show visible cracks, the Er,Cr:YSGG treated surfaces showed significant surface cracks. They reported that this resulted in significant weakening for the Er,Cr:YSGG treated specimens. This was explained by the q-switch laser generating mechanical and thermal shock waves, thermal expansion, and recoiling ablation debris [23]. It is to be noted that in addition to the drastically reduced pulse duration ( 135 versus $0.5 \mu \mathrm{s})$ the irradiation with the Er,Cr:YSGG laser was also performed without a water spray which represents an experimental setup which does not simulate a clinical situation.

Therefore, in the presented study, the pulse durations meet clinical requirements for dentin preparation with pulse durations of $50-100 \mu$ s typically found on free-running systems (flash-lamp operated). It is noteworthy that q-switched erbium lasers are so far not used clinically in dentistry and that it is well known that water sprays must be used during hard tissue preparations.

In our study, fracture strengths of dentinal beams irradiated with Er:YAG and Er,Cr:YSGG laser were compared with bur preparation and untreated intact beams in a 4-point bending test. There were no significant differences among groups. $4 \mathrm{~J} / \mathrm{cm}^{2}$ for Er:YAG laser irradiation has already been reported as the ablation threshold for dentin preparation $[23,24]$. The fluencies above the ablation threshold for dentin preparation were selected in order to simulate a cavity floor on the surface of the dentin beams within the limits of our experimental setup. With the settings used in the present investigation laser irradiation did not weaken the dentinal beams in comparison with intact beams or bur treated beams.

The Er:YAG laser was compared by Sehy and Drummond with coarse diamond bur for preparation of class I and II MOD cavities that were restored by bulk curing composite restoration and no visible evidence of microcracking was found [22].

However in a study of fatigue crack growth rates by Nalla et al. in human dentin, it was concluded that, under simulated physiologic conditions, small flaws in teeth, in the order of $250 \mu \mathrm{m}$, will not radically affect their structural integrity as the predicted fatigue lifetime will exceed that of the patient [34]. For this reason we included group 2 (fine diamond bur in a high speed hand piece with water cooling) as positive control to include the possible effect of structural weakening under mechanical treatment of the surface. Another study by Bosa et al. utilizing a q-switched Er:YSGG laser reported on minimal thermal damage to the specimens while observing mechanical damage at higher fluencies [35].

Near infrared imaging of enamel samples irradiated by an industrial marking laser, operating at a wavelength of $9.3 \mu \mathrm{m}$ with a repetition rate of $300 \mathrm{~Hz}$, compared the peripheral thermal and mechanical damage produced by a standard dental hand piece with a high speed air turbine with the laser. Here 2 out of 15 (13.3\%) irradiated samples were reported to have small cracks next to the ablation craters [21]. Without a water spray, mechanical as well as thermal damage occurred. Compared to this, 9 of $15(60 \%)$ samples prepared with a high speed bur exhibited mechanical damage in the form of cracking and evidence of thermal damage [21].

In the present study, constant water spray was used during the whole laser irradiation process for both Er:YAG and Er,Cr:YSGG lasers, as it is also used in clinical treatments of enamel and dentin, either for cavity preparation or for other surface modifications. The importance of continuous spray application is also confirmed by Darling et al. who observed "very clean without large cracks" ablation craters and no accompanying thermal side effects [19]. The water spray acts as a mediator for efficient ablation and minimizes the risk of adverse thermal effects in the pulp tissue. The excessive increase of intrapulpal temperature and the possible thermal damage to the hard dental tissues have restricted Er:YAG laser ablation on dry teeth. Water sprays are, therefore, essential to reduce the side effects of temperature rise on biological tissues during clinical applications of Er:YAG lasers [36-39]. It has been shown that water cooling is essential to avoid destructive temperature increase whether an erbium laser or a high speed hand piece is used for cavity preparation [40]. The water spray is used to clean the irradiated surface, supply a cooling effect, and assist the ablation process $[41,42]$. Additionally, the use of Er:YAG lasers without water spray has been reported to cause formation of non-apatite calcium phosphate phases which may be prone to acid dissolution and demineralization and may eventually lead to insufficient bonding of restorations [43].

In a study by Arola and Rouland the rate of fatigue crack growth was evaluated in terms of the dentin tubule orientation and tubule density. They concluded that fatigue 
crack growth in dentin is dependent on the tubule orientation [7]. For this reason the treated surface of dentin beams in our study was marked in such a way that tubules were perpendicular to the treated surface and in the same orientation for all samples. During the bending test the treated surfaces of the samples were positioned on the tensile side so the load is applied in the same direction in which it occurs naturally.

However, it is important to note that the presented study is to be interpreted with its limitations in mind. We investigated the influence of treatments and irradiations which are expected to influence the material close to the surface for the reason of simulating a standardized cavity floor. However, this situation does not include all effects that may be present in a clinical cavity preparation. For instance, effects such as shock or pressure waves created with higher fluencies and pulse powers are not present in our model. For flash-lamp pumped erbium lasers these shock waves are unlikely to have an effect, if present at all, as was described by Hibst and Keller [44]. Shock waves are more of a concern when pulse durations drop below $1 \mu \mathrm{s}$ as is the case when using q-switched lasers [23]. Another effect not modeled in our in vitro situation is the act of mechanical drilling into the tooth during an actual cavity preparation; however, this may be partly compensated with the mechanical stress the teeth had experienced when being sawed apart to manufacture the dentin beam specimens from them. Additionally, the thermal influence of drilling into a tooth with clinical parameters has to be taken into account. While thermal weakening of the substance may in principle be possible, the appropriate use of the water sprays of free-running erbium lasers prevents a thermal increase, as was confirmed experimentally by Rizoiu et al. for the case of the Er,Cr:YSGG type system, where even a decrease in temperature of approx. $2^{\circ} \mathrm{C}$ was observed [45].

\section{Conclusion}

Within the conditions and limitations used in this study no statistically significant difference could be observed in the fracture strength of dentin beams when treating them either with Er:YAG and Er,Cr:YSGG laser irradiation or mechanically by a fine diamond bur in a high speed hand piece. Additionally, no statistically significant difference could be observed between treated and untreated specimens.

\section{Conflict of Interests}

The authors declare that there is no conflict of interests regarding the publication of this paper.

\section{References}

[1] H. H. K. Xu, J. R. Kelly, S. Jahanmir, V. P. Thompson, and E. D. Rekow, "Enamel subsurface damage due to tooth preparation with diamonds," Journal of Dental Research, vol. 76, no. 10, pp. 1698-1706, 1997.

[2] D. Arola, M. P. Huang, and M. B. Sultan, "The failure of amalgam dental restorations due to cyclic fatigue crack growth," Journal of Materials Science: Materials in Medicine, vol. 10, no. 6, pp. 319-327, 1999.
[3] A. Banerjee, E. A. M. Kidd, and T. F. Watson, "Scanning electron microscopic observations of human dentine after mechanical caries excavation," Journal of Dentistry, vol. 28, no. 3, pp. 179$186,2000$.

[4] J. J.-W. Lee, J.-Y. Kwon, H. Chai, P. W. Lucas, V. P. Thompson, and B. R. Lawn, "Fracture modes in human teeth," Journal of Dental Research, vol. 88, no. 3, pp. 224-228, 2009.

[5] J. J. Kruzic, R. K. Nalla, J. H. Kinney, and R. O. Ritchie, "Mechanistic aspects of in vitro fatigue-crack growth in dentin," Biomaterials, vol. 26, no. 10, pp. 1195-1204, 2005.

[6] D. Arola and R. K. Reprogel, "Effects of aging on the mechanical behavior of human dentin," Biomaterials, vol. 26, no. 18, pp. 4051-4061, 2005.

[7] D. D. Arola and J. A. Rouland, The Effects of Tubule Orientation on Fatigue Crack Growth in Dentin, John Wiley \& Sons, New York, NY, USA, 2003.

[8] J. Ivancik, N. K. Neerchal, E. Romberg, and D. Arola, “The reduction in fatigue crack growth resistance of dentin with depth," Journal of Dental Research, vol. 90, no. 8, pp. 1031-1036, 2011.

[9] S. Ratcliff, I. M. Becker, and L. Quinn, "Type and incidence of cracks in posterior teeth," Journal of Prosthetic Dentistry, vol. 86, no. 2, pp. 168-172, 2001.

[10] H. Ryou, N. Amin, A. Ross et al., "Contributions of microstructure and chemical composition to the mechanical properties of dentin," Journal of Materials Science: Materials in Medicine, vol. 22, no. 5, pp. 1127-1135, 2011.

[11] T. F. Watson and R. J. Cook, "The influence of bur blade concentricity on high-speed tooth-cutting interactions: a videorate confocal microscopic study," Journal of Dental Research, vol. 74, no. 11, pp. 1749-1755, 1995.

[12] J. Yan, B. Taskonak, and J. J. Mecholsky Jr., "Fractography and fracture toughness of human dentin," Journal of the Mechanical Behavior of Biomedical Materials, vol. 2, no. 5, pp. 478-484, 2009.

[13] H. Majd, J. Viray, J. A. Porter, E. Romberg, and D. Arola, "Degradation in the fatigue resistance of dentin by bur and abrasive air-jet preparations," Journal of Dental Research, vol. 91, no. 9, pp. 894-899, 2012.

[14] M. C. L. Luengo, M. Portillo, J. M. Sánchez et al., "Evaluation of micromorphological changes in tooth enamel after mechanical and ultrafast laser preparation of surface cavities," Lasers in Medical Science, vol. 28, no. 1, pp. 267-273, 2013.

[15] S. A. M. Corona, A. E. De Souza, M. A. Chinelatti, M. C. Borsatto, J. D. Pécora, and R. G. Palma-Dibb, "Effect of energy and pulse repetition rate of Er: YAG laser on dentin ablation ability and morphological analysis of the laser-irradiated substrate," Photomedicine and Laser Surgery, vol. 25, no. 1, pp. 26-33, 2007.

[16] C. Fornaini, S. Petruzzella, R. Podda, E. Merigo, S. Nammour, and P. Vescovi, "Er:YAG laser and fractured incisor restorations: an in vitro study," International Journal of Dentistry, vol. 2012, Article ID 617264, 6 pages, 2012.

[17] K. Takamori, H. Furukawa, Y. Morikawa, T. Katayama, and S. Watanabe, "Basic study on vibrations during tooth preparations caused by high-speed drilling and Er:YAG laser irradiation," Lasers in Surgery and Medicine, vol. 32, no. 1, pp. 25-31, 2003.

[18] R. J. G. De Moor and K. I. M. Delmé, "Laser-assisted cavity preparation and adhesion to erbium-lased tooth structure: part 1. Laser-assisted cavity preparation," The Journal of Adhesive Dentistry, vol. 11, no. 6, pp. 427-438, 2009. 
[19] C. L. Darling, M. E. Maffei, W. A. Fried, and D. Fried, "NearIR imaging of erbium laser ablation with a water spray," in Proceedings of the 14th World Congress for Laser Dentistry, vol. 6843 of Proceedings of SPIE, San Jose, Calif, USA, January 2003.

[20] V. Colucci, F. L. B. do Amaral, J. D. Pécora, R. G. PalmaDibb, and S. A. Milori Corona, "Water flow on erbium:yttriumaluminum-garnet laser irradiation: effects on dental tissues," Lasers in Medical Science, vol. 24, no. 5, pp. 811-818, 2009.

[21] L. H. Maung, C. Lee, and D. Fried, "Near-IR imaging of thermal changes in enamel during laser ablation," Proceedings of the International Society for Optical Engineering, vol. 7546, no. 1, p. 754902, 2010.

[22] C. Sehy and J. L. Drummond, "Micro-cracking of tooth structure," American Journal of Dentistry, vol. 17, no. 5, pp. 378-380, 2004.

[23] M. Staninec, N. Meshkin, S. K. Manesh, R. O. Ritchie, and D. Fried, "Weakening of dentin from cracks resulting from laser irradiation," Dental Materials, vol. 25, no. 4, pp. 520-525, 2009.

[24] B. Majaron, M. Lukac, D. Susteric, N. Funduk, and U. Skaleric, "Threshold and efficiency analysis in Er:YAG laser ablation of hard dental tissue," in Laser Applications in Medicine and Dentistry, vol. 2922 of Proceedings of SPIE, pp. 233-242, Vienna, Austria, September 1996.

[25] P. M. Freitas, R. S. Navarro, J. A. Barros, and C. D. P. Eduardo, "The use of Er:YAG laser for cavity preparation: an SEM evaluation," Microscopy Research and Technique, vol. 70, no. 9, pp. 803-808, 2007.

[26] K. I. M. Delmé and R. J. G. De Moor, "Scanning electron microscopic evaluation of enamel and dentin surfaces after Er:YAG laser preparation and laser conditioning," Photomedicine and Laser Surgery, vol. 25, no. 5, pp. 393-401, 2007.

[27] R. S. Navarro, S. Gouw-Soares, A. Cassoni, P. Haypek, D. M. Zezell, and C. De Paula Eduardo, "The influence of erbium:yttrium-aluminum-garnet laser ablation with variable pulse width on morphology and microleakage of composite restorations," Lasers in Medical Science, vol. 25, no. 6, pp. 881$889,2010$.

[28] W. Raucci-Neto, M. A. Chinelatti, and R. G. Palma-Dibb, "Ablation rate and morphology of superficial and deep dentin irradiated with different Er:YAG laser energy levels," Photomedicine and Laser Surgery, vol. 26, no. 6, pp. 523-529, 2008.

[29] W. Raucci-Neto, J. D. Pécora, and R. G. Palma-Dibb, “Thermal effects and morphological aspects of human dentin surface irradiated with different frequencies of Er:YAG laser," Microscopy Research and Technique, vol. 75, no. 10, pp. 1370-1375, 2012.

[30] A. Igarashi, J. Kato, Y. Takase, and Y. Hirai, "Influence of output energy and pulse repetition rate of the Er:YAG laser on dentin ablation," Photomedicine and Laser Surgery, vol. 26, no. 3, pp. 189-195, 2008.

[31] M. A. Chinelatti, W. Raucci-Neto, S. A. M. Corona, and R. G. Palma-Dibb, "Effect of erbium:yttrium-aluminum-garnet laser energies on superficial and deep dentin microhardness," Lasers in Medical Science, vol. 25, no. 3, pp. 317-324, 2010.

[32] J. Pelagalli, C. B. Gimbel, R. T. Hansen, A. Swett, D. W. Winn II, and M. Van Valen, "Investigational study of the use of Er:YAG laser versus dental drill for caries removal and cavity preparation-phase I," Journal of Clinical Laser Medicine and Surgery, vol. 15, no. 3, pp. 109-115, 1997.

[33] R. Lubart, G. Kesler, R. Lavie, and H. Friedmann, "Er:YAG laser promotes gingival wound repair by photo-dissociating water molecules," Photomedicine and Laser Surgery, vol. 23, no. 4, pp. 369-372, 2005.
[34] R. K. Nalla, V. Imbeni, J. H. Kinney, M. Staninec, S. J. Marshall, and R. O. Ritchie, "In vitro fatigue behavior of human dentin with implications for life prediction," Journal of Biomedical Materials Research, Part A, vol. 66, no. 1, pp. 10-20, 2003.

[35] A. D. Bosa, A. V. Sarma, C. Q. Le, R. S. Jones, and D. Fried, "Peripheral thermal and mechanical damage to dentin with microsecond and sub-microsecond $9.6 \mu \mathrm{m}, 2.79 \mu \mathrm{m}$, and 0.355 $\mu \mathrm{m}$ laser pulses," Lasers in Surgery and Medicine, vol. 35, no. 3, pp. 214-228, 2004.

[36] E. J. Burkes Jr., J. Hoke, E. Gomes, and M. Wolbarsht, "Wet versus dry enamel ablation by Er:YAG laser," The Journal of Prosthetic Dentistry, vol. 67, no. 6, pp. 847-851, 1992.

[37] M. Hossain, Y. Nakamura, Y. Yamada, Y. Kimura, G. Nakamura, and K. Matsumoto, "Ablation depths and morphological changes in human enamel and dentin after Er:YAG laser irradiation with or without water mist," Journal of Clinical Laser Medicine and Surgery, vol. 17, no. 3, pp. 105-109, 1999.

[38] V. R. Geraldo-Martins, E. Y. Tanji, N. U. Wetter, R. D. Nogueira, and C. P. Eduardo, "Intrapulpal temperature during preparation with the Er:YAG laser: an in vitro study," Photomedicine and Laser Surgery, vol. 23, no. 2, pp. 182-186, 2005.

[39] J. Meister, R. Franzen, K. Forner et al., "Influence of the water content in dental enamel and dentin on ablation with erbium YAG and erbium YSGG lasers," Journal of Biomedical Optics, vol. 11, no. 3, Article ID 034030, 2006.

[40] B. N. Cavalcanti, J. L. Lage-Marques, and S. M. Rode, "Pulpal temperature increases with Er:YAG laser and high-speed handpieces," Journal of Prosthetic Dentistry, vol. 90, no. 5, pp. 447451, 2003.

[41] K. Glockner, J. Rumpler, K. Ebeleseder, and P. Städtler, "Intrapulpal temperature during preparation with the Er:YAG laser compared to the conventional burr: an in vitro study," Journal of Clinical Laser Medicine and Surgery, vol. 16, no. 3, pp. 153-157, 1998.

[42] D. Oelgiesser, J. Blasbalg, and A. Ben-Amar, "Cavity preparation by Er:YAG laser on pulpal temperature rise," American Journal of Dentistry, vol. 16, no. 2, pp. 96-98, 2003.

[43] D. Fried, N. Ashouri, T. Breunig, and R. Shori, "Mechanism of water augmentation during IR laser ablation of dental enamel," Lasers in Surgery and Medicine, vol. 31, no. 3, pp. 186-193, 2002.

[44] R. Hibst and U. Keller, "Mechanism of Er:YAG laser-induced ablation of dental hard substances," in Proceedings of the Lasers in Orthopedic, Dental, and Veterinary Medicine II, vol. 1880 of Proceedings of SPIE, Los Angeles, Calif, USA, July 1993.

[45] I. Rizoiu, F. Kohanghadosh, A. I. Kimmel, and L. R. Eversole, "Pulpal thermal responses to an erbium,chromium:YSGG pulsed laser hydrokinetic system," Oral Surgery, Oral Medicine, Oral Pathology, Oral Radiology, and Endodontics, vol. 86, no. 2, pp. 220-223, 1998. 


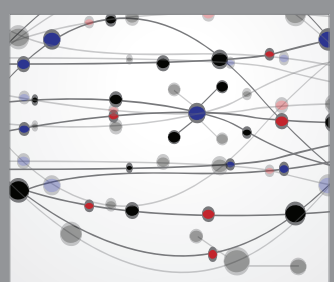

The Scientific World Journal
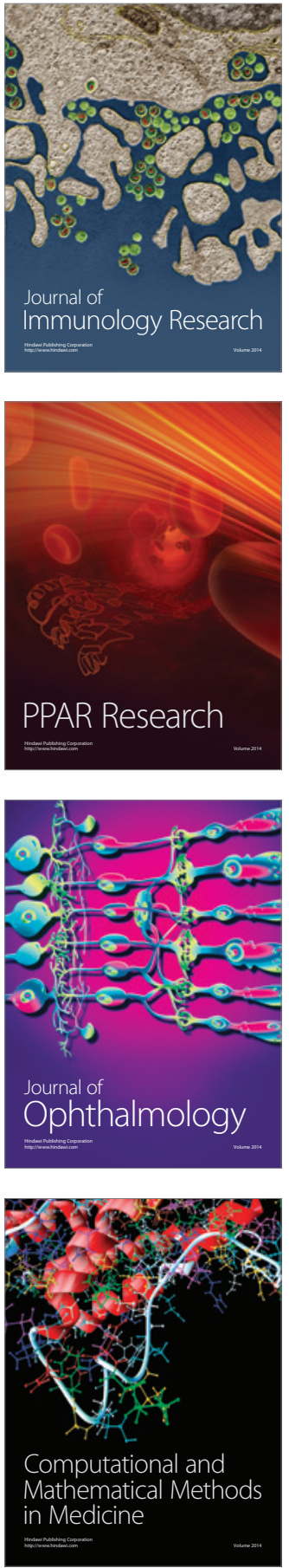

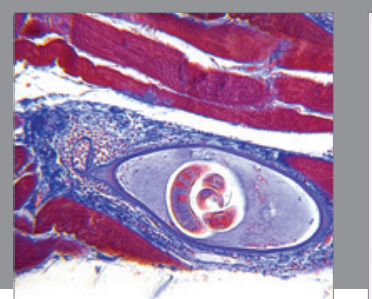

Gastroenterology Research and Practice

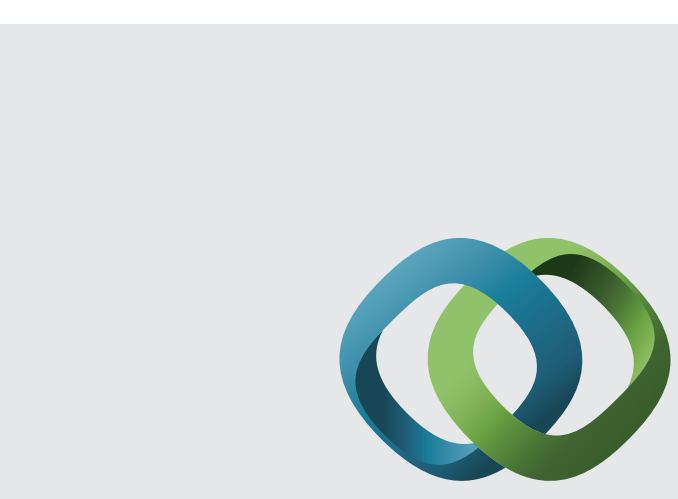

\section{Hindawi}

Submit your manuscripts at

http://www.hindawi.com
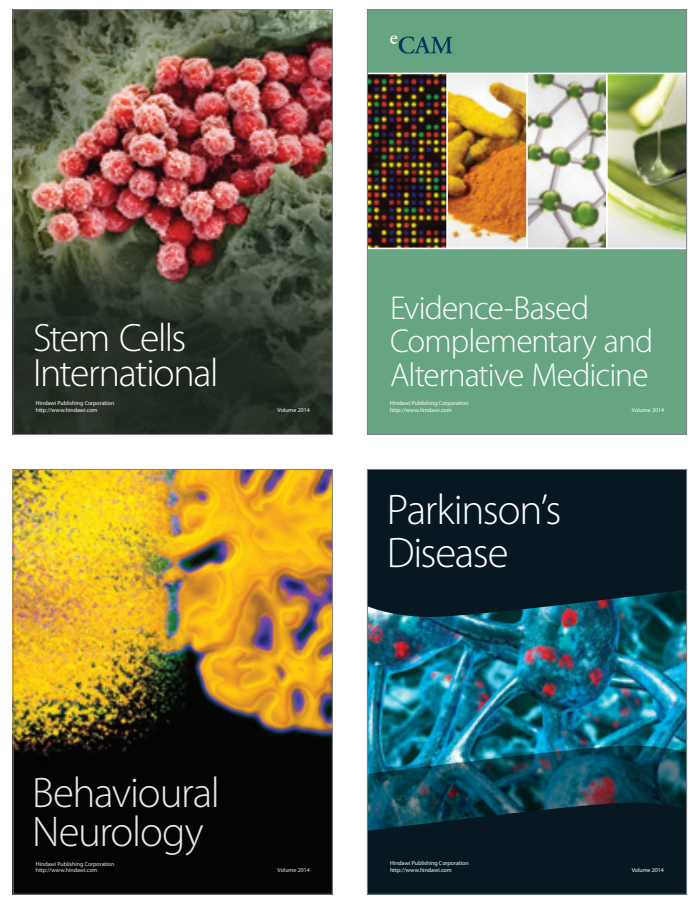
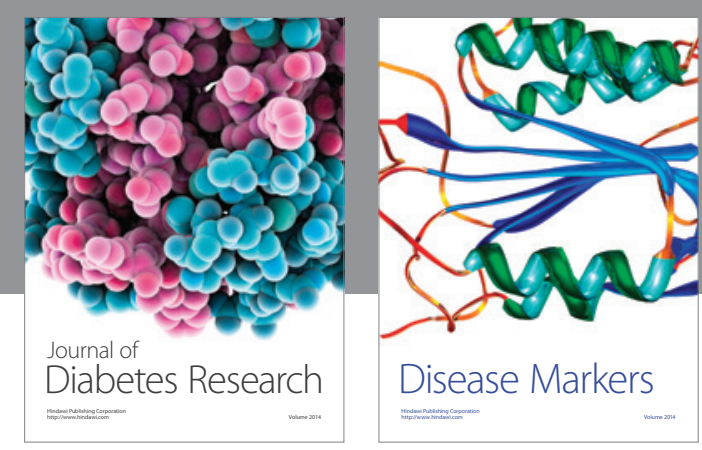

Disease Markers
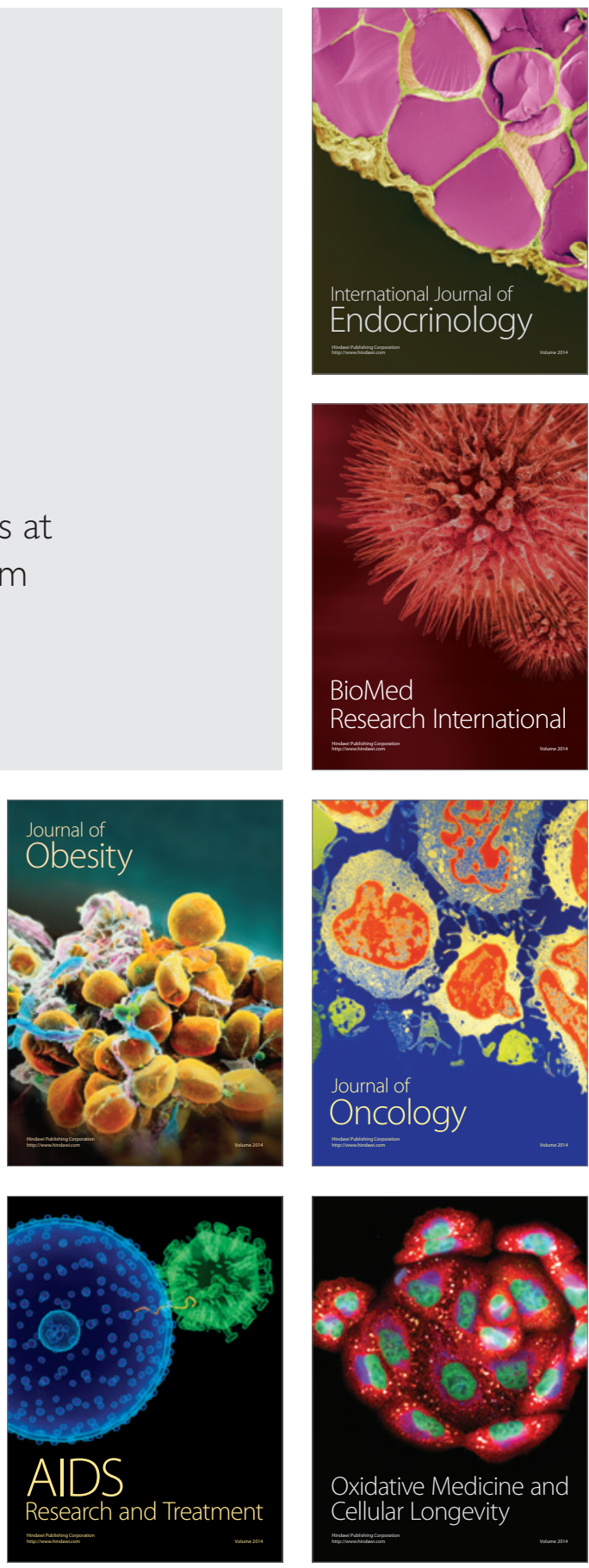